\title{
ESTUDO DA FORMAÇÃO DE BIOFILMES POR PSEUDOMONAS AERUGINOSA
}

Marcos Antônio Batista Caixeta ${ }^{1}$, Ananda da Silva Braga ${ }^{1}$, Débora Godói Souza de Almeida $^{2}$, Osvaldo Gomes Pinto ${ }^{3}$, Eliete Sousa Santana ${ }^{4}$, Plínio Lázaro Faleiro Naves $^{5}$

${ }^{1}$ Bacharel em Farmácia - Campus Anápolis de Ciências Exatas e Tecnológicas Universidade Estadual de Goiás - Brasil.

${ }^{2}$ Acadêmica do curso de Farmácia - Campus Anápolis de Ciências Exatas e Tecnológicas Universidade Estadual de Goiás - Brasil.

${ }^{3}$ Técnico do Laboratório de Microbiologia, mestrando do Programa de Ciências Aplicadas a Produtos para Saúde - Campus Anápolis de Ciências Exatas e Tecnológicas Universidade Estadual de Goiás - Brasil.

${ }^{4}$ Professora Doutora do Campus Anápolis de Ciências Exatas e Tecnológicas Universidade Estadual de Goiás - Brasil.

${ }^{5}$ Professor Doutor do Campus Anápolis de Ciências Exatas e Tecnológicas Universidade Estadual de Goiás - Brasil.

E-mail: plinionaves@ueg.br

Recebido em: 06/04/2019 - Aprovado em: 10/06/2019 - Publicado em: 30/06/2019 DOI: 10.18677/EnciBio_2019A144

\begin{abstract}
RESUMO
A formação de biofilme por Pseudomonas aeruginosa propicia o aumento da patogenicidade e resistência desse micro-organismo a condições adversas. $\mathrm{Na}$ forma séssil, a $P$. aeruginosa pode ser resistente a concentrações inibitórias 100 vezes maiores do que quando crescendo na forma planctônica. Este trabalho teve como objetivo estudar a formação de biofilmes por $P$. aeruginosa em microplacas de poliestireno nos meios de cultura de caldo de Soja Tripticaseína (TSB) e Água Peptonada (AP) com incubações de 24 e 48 horas para a quantificação da biomassa total formada pelo método do cristal violeta. Foram utilizadas cepas-padrão de $P$. aeruginosa American Type Culture Collection (ATCC 9027 e ATCC 27853) e um isolado de fígado de frango comercial. Os resultados permitiram a otimização da técnica por meio da determinação que as melhores condições para formação de biofilme ocorreram em caldo mais nutritivo (TSB) com o tempo de incubação de $24 \mathrm{~h}$ para as cepas-padrão, enquanto que $o$ isolado de fígado de frango apresentou baixos níveis de formação de biofilme de forma semelhante nas condições avaliadas. A partir dos resultados obtidos, pode-se concluir que o caldo de cultura com maior disponibilidade de nutrientes propiciou maior formação de biofilme das cepas-padrão de $P$. aeruginosa em $24 \mathrm{~h}$ de incubação.
\end{abstract}

PALAVRAS-CHAVE: adesão bacteriana, biomassa total, cristal violeta.

\section{STUDY OF THE FORMATION OF BIOFILMS BY PSEUDOMONAS AERUGINOSA}

\section{ABSTRACT}

Biofilm formation by Pseudomonas aeruginosa can provide increased pathogenicity and resistance to adverse conditions such as the antimicrobials agents resistence that may be ineffective against sessile forms, even at concentrations 100 times 
greater than the same bacteria when growing in planktonic form. The aim of this work was to study the formation of biofilms by $P$. aeruginosa in polystyrene microplates in the broth media of Trypticase (TSB) Soybean Broth and Peptonated Water (AP) with incubation of 24 and $48 \mathrm{~h}$ for the quantification of total biomass formed by crystal violet method. Standard strains of $P$. aeruginosa American Type Culture Collection (ATCC 9027 and ATCC 27853) and a commercial chicken liver isolate were used. The results allowed the optimization of the technique and determination of the best conditions for biofilm formation occurred in more nutritive broth (TSB) with the incubation time of $24 \mathrm{~h}$ for the standard strains while the chicken liver isolate presented low levels of formation of biofilm a similar way under the conditions evaluated. From the obtained results it can be concluded that the broth of culture with greater availability of nutrients propitiated to greater biofilm formation of standard strains of $P$. aeruginosa in $24 \mathrm{~h}$ of incubation.

KEYWORDS: Bacterial adhesion, total biomass, crystal violet.

\section{INTRODUÇÃO}

Biofilmes são comunidades microbianas compostas por uma ou mais espécies aderidas a um substrato embebido em uma matriz de polímeros extracelulares denominados exopolissacarídeos (EPS). As bactérias sésseis se diferenciam das formas livres planctônicas, tanto do ponto de vista fenotípico como genotípico (HA; O'TOOLE, 2015).

A síntese e organização dos componentes da matriz para formação do biofilme é um processo dinâmico e altamente complexo que envolve a expressão coordenada e transcrição de vários genes e que se difere entre as diversas linhagens bacterianas existentes (VADYVALOO; MARTíNEZ, 2014).

A formação dessa estrutura microbiana é constituída pela sucessão das etapas de adesão inicial, mudança de vida planctônica para séssil, formação de microcolônias, maturação, destacamento de células planctônicas ou para colonização de outro sítio. Essas estruturas podem ocorrer em vários tipos de ambientes, sejam bióticos ou abióticos (HA; O'TOOLE, 2015). Já os estágios de formação do biofilme é um processo mais conservador, entretanto, envolve diversas etapas, as quais são governadas por uma série de processos físico-químicos e biológicos (VADYVALOO; MARTíNEZ, 2014).

A primeira etapa do processo de formação do biofilme, começa pela adesão reversível de bactérias planctônicas, sobre uma superfície adequada para 0 crescimento, seguido pela fixação irreversível de bactérias que posteriormente, formam microcolônias na matriz de EPS (RASAMIRAVAKA et al., 2015). Substrato e célula bacteriana podem influenciar essa adesão inicial a superfícies inertes por meio de suas propriedades, por exemplo; hidrofobicidade, rugosidade superficial, presença de fímbrias, flagelos e produção de EPS. Fatores como temperatura, $\mathrm{pH}$, tempo de incubação ou composição do meio de cultura são capazes de afetar as propriedades das células bacterianas em iniciar a adesão (KALICIŃSKA; TYSKI, 2009).

Pseudomonas aeruginosa é um micro-organismo com extensa difusão detectado no meio ambiente, nas superfícies de plantas, no solo, na água e podem fazer parte da microbiota intestinal em seres humanos (DE FREITAS et al., 2018). Este micro-organismo apresenta resistência antimicrobiana natural ou adquirida, devido a fatores como a capacidade metabólica flexível e seu genoma que codifica uma série de genes de resistência como os sistemas de efluxo da família RND resistance-nodulation-cell division (MULCAHY et al., 2014). 
Pseudomonas aeruginosa, Escherichia coli e Burkholderia cepacia se destacam no crescimento em biofilmes. Estas são capazes de tirar partido na formação de biofilmes e aumentar a resistência a fatores como a proteção contra antimicrobianos, desinfetantes, sistema imune inato e a várias influências ambientais negativas, permitindo-lhes assim, abranger vários nichos ambientais e colonizar diversas matrizes de tecido, solo e planta, fato que não é necessariamente observado nas mesmas bactérias quando se desenvolve na forma planctônica (MASÁK et al., 2014; MULCAHY et al., 2014; RIBEIRO et al. 2016).

Várias espécies do gênero Pseudomonas são usadas na área da biotecnológica ambiental como em processos de biorremediação (KABENGE et al., 2017). Porém, no que concerne à capacidade de formação de biofilmes, $P$. aeruginosa apresenta maior relevância, devido à morbimortalidade causada pela infecção por este patógeno oportunista em muitas doenças recorrentes e persistentes que, frequentemente, acometem pacientes debilitados ou imunocomprometidos (MASÁK et al., 2014; MULCAHY et al., 2014).

Diversas infecções nosocomiais estão associadas à formação do biofilme em sistema de ventilação, abastecimento de água, feridas crônicas e instrumentos médicos como superfícies de cateteres, bisturis, marca-passos, válvulas cardíacas (MULCAHY et al. 2014). Os biofilmes também podem se formar rapidamente nas indústrias de alimentos e provocar infecções ou intoxicações relacionadas as substâncias produzidas pelas matrizes do biofilme. Isso ocorre devido à capacidade de fixação em superfícies abióticas como luvas, materiais de embalagens, superfícies de distribuição e armazenamento de alimentos, equipamentos industriais e a fixação em superfícies bióticas como carnes, vegetais, ossos, dentre outros o que possibilita maior risco de contaminação bacteriana (SPERANZA; CORBO, 2017; GALIE et al., 2018).

Existem diversos protocolos que foram propostos ao longo dos anos para analisar a formação relativa de biofilme, dentre estes, os mais comuns são relacionados à análise de biofilme estático, sendo realizados em microplacas de 96 poços, permitindo uma triagem de alto rendimento para quantificar 0 crescimento de biofilme em que se destacam os métodos baseados em corantes, como cristal violeta, safranina e outros corantes metabólicos como resazurina (HANEY et al., 2018).

Uma abordagem que permite a análise de formação do biofilme e susceptibilidade antimicrobiana é o dispositivo Calgary Biofilm que possibilita o crescimento de biofilmes em pinos suspensos em uma tampa de placa de microtitulação. Entretanto, este ainda é de alto custo para pesquisas. Contudo, o método de coloração com cristal violeta que se liga às moléculas de superfície carregadas negativamente e a polissacarídeos da matriz extracelular é considerado "padrão ouro" para quantificação de biofilmes em microplaca, uma vez que consiste em um ensaio de baixo custo relativo e de fácil reprodutibilidade (O'TOOLE, 2011).

A definição das melhores condições para formação de biofilme pelas cepas estudadas e a quantificação da adesão através da biomassa total formada pelos biofilmes nos meios de cultura estudados e necessária para se estabelecer protocolos definidos para o estudo da formação de biofilmes, considerando o melhor meio de cultura e intervalo de incubação, empregando-se a metodologia de ensaio colorimétrico com cristal violeta, de modo que seja um método rápido, confiável, de baixo custo, alto rendimento e adaptável. 
Portanto, visto que a formação de biofilmes bacteriano acarreta inúmeras repercussões em diversas áreas, este trabalho objetivou estudar este fenômeno em cepas de Pseudomonas aeruginosa incubadas em microplacas de poliestireno nos meios de cultura - caldos de soja tripticaseína (TSB) e água pepetonada (AP) com a incubação de 24 e 48h, com vistas a otimização dos ensaios de formação do biofilme por esta bactéria.

\section{Micro-organismos utilizados no estudo \\ MATERIAL E MÉTODOS}

Para a realização dos ensaios foram utilizadas cepas-padrão de Pseudomonas aeruginosa (ATCC 9027 e 27853) provenientes da coleção do Laboratório de Microbiologia da Universidade Estadual de Goiás (UEG - CCET) e um isolado de fígado de frango comercial coletado em abatedouro frigorífico do estado de Goiás sob sistema de inspeção estadual, gentilmente cedido pela profa. Dra. Maria Auxiliadora Andrade da Escola de Veterinária da Universidade Federal de Goiás.

\section{Manutenção e reativação das cepas estudadas}

A manutenção das cepas foi realizada conforme descrito por Silva et al. (2008), com pequenas modificações. Primeiramente, foram realizados repiques das cepas, a fim de se obter colônias isoladas. As cepas foram repicadas em ágar cetrimida e as placas incubadas a $35^{\circ} \mathrm{C}$ por 24 horas. Logo em seguida, foram transferidas de três a cinco colônias isoladas e típicas para um tubo com $15 \mathrm{~mL}$ de caldo Nutriente $+20 \%$ de glicerol, em seguida o conteúdo foi homogenizado em agitador de tubos por 15 segundos, após este procedimento, os tubos foram incubados por 12 horas a $35^{\circ} \mathrm{C}$. Após a incubação, foram transferidas alíquotas de 1 $\mathrm{mL}$ para microtubos tipo Eppendorf, previamente esterilizados e devidamente rotulados e armazenadas a $8 \stackrel{\circ}{\circ}$ por sete dias e congelados em freezer a $-30 \stackrel{\circ}{\circ}$. As cepas foram reativadas em ágar cetrimida, pela técnica de esgotamento por estrias. As placas foram semeadas e em seguida, incubadas a $35^{\circ} \mathrm{C}$ por 24 horas.

\section{Produção de biofilmes "in vitro" em microplacas: determinação da biomassa total (polissacarídeos e bactérias)}

Foi utilizada a metodologia descrita por Stepanovic et al. (2004) com algumas modificações. Resumidamente, colônias típicas e isoladas de $P$. aeruginosa foram suspensas em $5 \mathrm{~mL}$ de solução fisiológica estéril $0,9 \%$ e a turvação foi ajustada

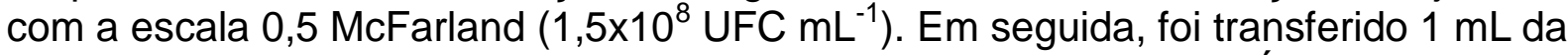
suspensão para $9 \mathrm{~mL}$ dos caldos de Soja Tripticaseína (TSB) e Água Peptonada

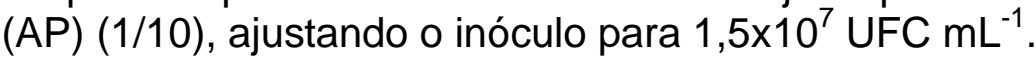

Em seguida, em cada poço de uma microplaca de poliestireno, contendo 100 $\mathrm{L}$ do meio de cultura TSB e AP, foram colocados $5 \mathrm{~L}$ da suspensão celular para o crescimento do biofilme $\left(1 \times 10^{5} \mathrm{UFC} \mathrm{mL}^{-1}\right)$, exceto nos poços controles negativos, nos quais foram colocados apenas $100 \mu \mathrm{L}$ dos meios de cultura.

As microplacas foram incubadas nos intervalos de $24 \mathrm{~h}$ e $48 \mathrm{~h}$. Após este período, foi feita a leitura visual, confirmando o crescimento das cepas e a não contaminação nos controles negativos. Posteriormente, os meios de cultura foram retirados dos poços e lavados três vezes com 200 L de solução fisiológica estéril para a remoção das células não aderidas.

Para os ensaios de estudo da biomassa total, as placas foram tratadas segundo metodologia descrita por Naves et al. (2008). Resumidamente, foram 
adicionados $110 \mu \mathrm{L}$ de cristal violeta $1 \%$ por 10 minutos, em seguida, o corante foi desprezado e as placas lavadas cinco vezes com $200 \mu \mathrm{L}$ de água destilada. As placas foram secas a $35{ }^{\circ} \mathrm{C}$ por 20 minutos, posteriormente, foram adicionados 110 $\mu \mathrm{L}$ de etanol absoluto em cada poço para solubilização da coloração das bactérias aderidas e a placa incubada durante 10 minutos. Posteriormente, as leituras das densidades ópticas (DO) dos poços foram realizadas por um leitor de placas automatizado (Epoch) a $492 \mathrm{~nm}$.

A partir das densidades ópticas obtidas foram calculadas a formação de biofilme pela seguinte fórmula: $F B=B A-P C$ (NAVES et al., 2008). Sendo que, $F B$ corresponde à formação do biofilme, $B A$ é a densidade óptica a $492 \mathrm{~nm}$ dos poços com as bactérias aderidas e $P C$ representa as densidades ópticas dos poços controle não inoculados. $O$ experimento para determinação da biomassa total está esquematizado na Figura 1.

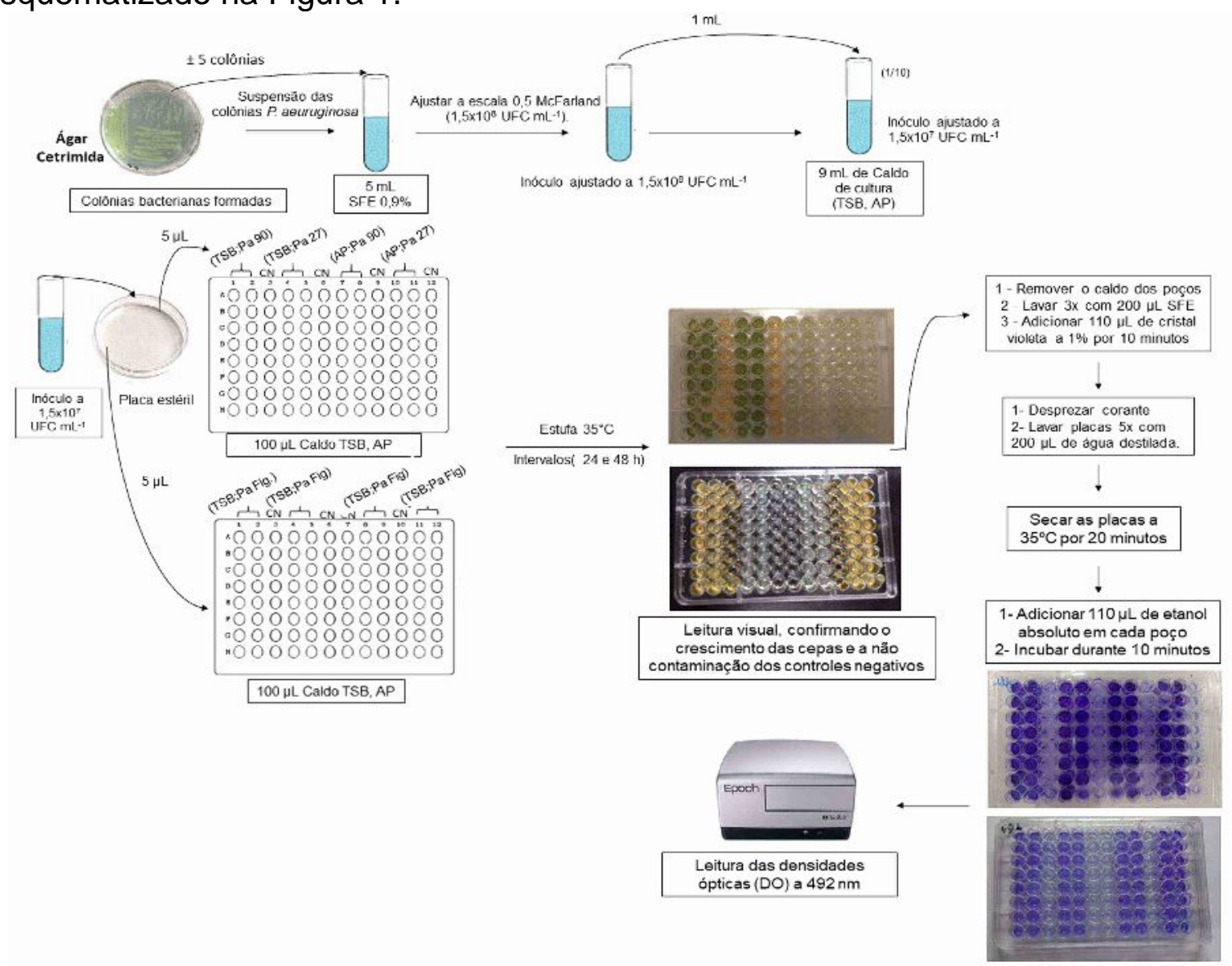

FIGURA 1 - Esquema da produção de biofilme em microplacas e determinação da biomassa total.

\section{Análises estatísticas}

Todos os experimentos foram realizados em triplicata e em ensaios independentes. As variáveis quantitativas geradas, índices de formação de biofilmes foram analisados descritivamente com o cálculo das médias e desvios padrão. Para avaliar o significado das diferenças entre a formação de biofilme nas diferentes condições testadas foi utilizado o teste T de Student pareado bicaudal $(p<0,01)$. 


\section{RESULTADOS E DISCUSSÃO}

$P$. aeruginosa ATCC 9027 apresentou melhor desempenho na formação de biofilmes, notadamente em caldo TSB, quando comparado ao da $P$. aeruginosa ATCC 27853 e ao isolado de fígado de frango comercial. Outro aspecto revelado é que todas as leituras obtidas para as cepas padrão com $24 \mathrm{~h}$ de incubação foram superiores às obtidas com $48 \mathrm{~h}$ e que o caldo TSB propiciou melhores índices de formação de biofilme, quando comparado à água peptonada (Figura 2).

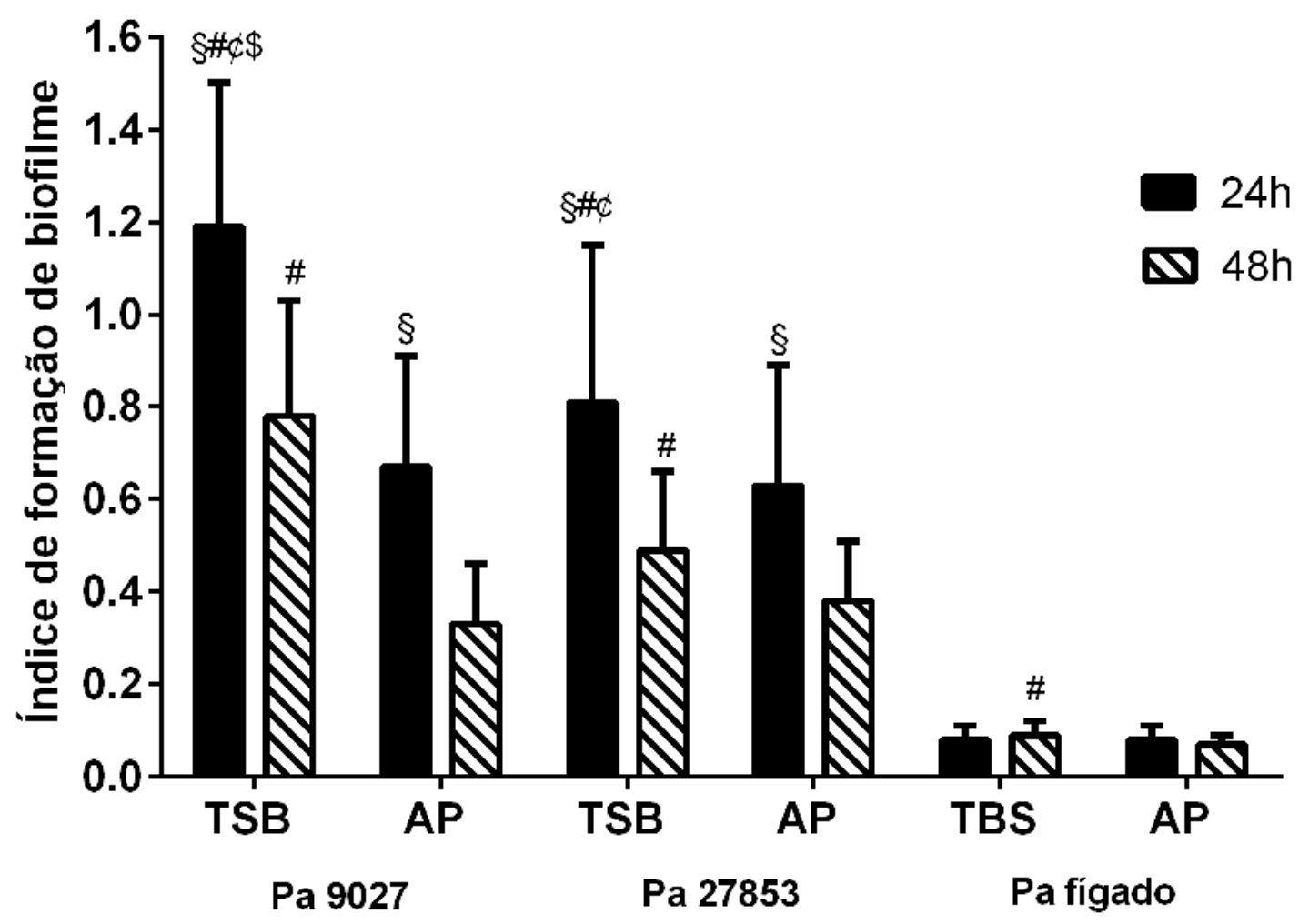

FIGURA 2 - Índices de formação de biofilmes de $P$. aeruginosa.

Legendas: Pa 9027 - Pseudomonas aeruginosa ATCC 9027, Pa 27853 Pseudomonas aeruginosa ATCC 27853, Pa fígado - Pseudomonas aeruginosa isolada de fígado de frango comercial, TSB - caldo de Soja Triptocaseína, AP Água Peptonada.

$\S$ - diferença estatisticamente significante entre os resultados de cada meio de cultura, nos tempos $24 \mathrm{~h}$ e $48 \mathrm{~h}$ de incubação (TSB 24h vs $48 \mathrm{~h}$; AP 24h vs $48 \mathrm{~h}$ ).

\# - diferença estatisticamente significante entre os resultados dos diferentes meios de cultura no mesmo tempo de incubação (TSB $24 \mathrm{~h}$ vs AP $24 \mathrm{~h}$, TSB 48h vs AP 48h).

c - diferença estatisticamente significante entre os resultados dos diferentes meios de cultura em diferentes tempos (TSB 24h vs AP 48h).

$\$$ - diferença estatisticamente significante entre os resultados das cepas em caldo TSB.

Conforme previamente descrito por Quatrin et al. (2016), os ensaios realizados em sistema fechado não permitem a renovação dos nutrientes e a remoção das substâncias tóxicas oriundas do metabolismo celular se acumulam no meio, esta característica do modelo experimental pode explicar porque os resultados da formação de biofilme nas primeiras 24 horas foram mais intensos em relação aos das placas incubadas por 48 horas. No entanto, o mesmo não foi verificado para a cepa obtida do isolado de frango que apresentou formação de biofilme semelhante para as incubações de $24 \mathrm{~h}$ e $48 \mathrm{~h}$. 
Diversos estudos, explorando vários tipos de bactérias, foram estabelecidos por Stepanovic et al. (2004) que mostraram que, de forma geral, o meio de cultura que produzia maior nível de células sésseis, variou para cada linhagem microbiana, no qual a inanição seria capaz de aumentar a adesão de alguns micro-organismos, ao passo que outros exibiam altas taxas de adesão em meio rico em nutrientes. Nestes estudos, eles confirmaram diferentes níveis de produção de biofilme, de acordo com o teor de nutrientes do meio, observando que para Salmonella spp. a adesão era maior em meio pobre em nutrientes, enquanto, para Listeria monocytogenes o meio rico em nutrientes propiciava mais formação de biofilme.

$\mathrm{O}$ caldo TSB é caracterizado como um meio altamente nutritivo e equilibrado, sendo este, de uso geral para o crescimento de uma grande variedade de micro-organismos, incluindo fungos e bactérias. No presente estudo, este meio proporcionou um ambiente mais adequado para o crescimento das bactérias e formação de biofilme. Em contraste, a água peptonada não propiciou as melhores condições para a formação de biofilme pelas bactérias estudadas. Este meio é considerado como mínimo para o crescimento, é empregado para realização de diluições seriadas de amostras para análise, transporte de micro-organismos e para pré-enriquecimento não seletivo.

A partir da análise dos resultados obtidos observou-se que a disponibilidade de nutrientes foi determinante para maior formação de biofilme, sugerindo interferência em relação ao nutriente do meio de cultura e capacidade da bactéria em expressar fatores de adesão, inclusive para a cepa obtida do isolado de frango, que apresentou desenvolvimento menos intenso com diferença das leituras de crescimento do biofilme somente após $48 \mathrm{~h}$ de incubação no caldo TSB, em comparação a água peptonada no mesmo período.

Ao analisar diferentes isolados de P. aeruginosa, Kalicińska e Tyski (2009); Perez e Barth (2011), utilizando metodologia semelhante ao do presente estudo, também reportaram maior capacidade de formação de biofilme sobre superfícies inertes, em concentrações mais elevadas de nutrientes.

Segundo Donlan (2002), o processo de ligação do micro-organismo à superfície sólida para formação do biofilme é um processo complexo regulado por diversas características como substrato, superfície celular e meio de crescimento, estando este último ainda pouco compreendido e, de acordo, com Shrout et al. (2006) uma possível explicação para a influência no desenvolvimento do biofilme de $P$. aeruginosa, pode estar relacionada a determinantes genéticos e ambientais, no qual o ambiente nutricional é capaz de modular a arquitetura do biofilme de acordo com a fonte de carbono utilizada para crescimento.

Laila e Santos (2016) descrevem também outro fator ligado a essas condições nutricionais para controlar a formação do biofilme, o sistema quorumsensing, sendo este importante por regular genes essenciais ao metabolismo, síntese proteica e de virulência, como os genes do biofilme.

\section{CONCLUSÕES}

Em nossas condições, a disponibilidade de nutrientes foi determinante para um maior índice de formação de biofilme de $P$. aeruginosa em caldo TSB. Alguns estudos demonstraram que a formação de biofilme é induzida em condições limitadas de nutrientes (MYSZKA; CZACZYK, 2009; NOWAK et al. 2015; GHANBARI et al. 2016), variando de acordo com cada linhagem microbiana e sua capacidade de expressar fatores de adesão. Sendo assim, a disponibilidade de nutrientes desempenha papel importante na transição, a partir de um modo de vida planctônico 
para um modo séssil e fatores como o tempo de incubação podem interferir na intensidade de biofilme formado. Neste estudo, P. aeruginosa ATCC 9027 apresentou melhor habilidade para formação de biofilme, podendo esta característica estar relacionada com a sua capacidade em expressar fatores de adesão mais habilmente que as outras cepas estudas.

No entanto, observa-se que o isolado de fígado de frango comercial apresentou uma menor capacidade de formação de biofilme em relação às outras cepas estudadas, mas que ainda sim justifica atenção com os cuidados com as condições de higienização nos ambientes de produção alimentar a fim de se minimizar a probabilidade de adesão de células e a formação de biofilmes na linha de processamento de alimentos e posteriormente, tornar-se uma fonte de contaminação cruzada.

Embora a existência de biofilmes tenha sido documentada há muitos anos, somente nas últimas décadas têm se destacado as ferramentas para estudar seus aspectos relacionados à formação e desenvolvimento. Isto graças a novas descobertas genéticas e moleculares, assim como, o desenvolvimento de novas técnicas de detecção da adesão bacteriana, permitindo avaliar o crescimento e adesão de um biofilme em uma dada área de superfícies. E como estas técnicas são normalizadas, possibilitam uma fácil reprodução e posterior comparação em outros trabalhos.

Portanto, o desenvolvimento de métodos sensíveis para a formação de biofilmes, revela-se uma questão importante, pois permite detalhar com mais precisão sobre sua estrutura e propriedades, além de ajudar a desenvolver métodos eficazes de erradicação do biofilme.

\section{AGRADECIMENTOS}

Ao Conselho Nacional de Desenvolvimento Científico e Tecnológico (CNPq) pelo financiamento da pesquisa concedido pelo Edital Universal oㅡ 01/2016 e a Universidade Estadual de Goiás, pela bolsa de iniciação cientifica (BIC) concedida pelo edital CCB 001/2017, aos dois últimos autores pelo Programa de Bolsa de Incentivo à Pesquisa e Produção Científica (PROBIP).

\section{REFERÊNCIAS}

DE FREITAS, M. B., MOREIRA, E. A. M., TOMIO, C., MORENO, Y. M. F., DALTOE, F. P., BARBOSA, E., GUARINO, A. Altered intestinal microbiota composition, antibiotic therapy and intestinal inflammation in children and adolescents with cystic fibrosis. PLOS ONE, v. 13, n. 6, p. e0198457, 2018. Disponível em: < https://journals.plos.org /plosone/article?id=10.1371/journal.pone.0198457> DOI: 10.1371 /journal.pone.0198 457

DONLAN, R. M. Biofilms: microbial life on surfaces. Emerging infectious diseases, v. 8, n. 9, p. 881, 2002. Disponível em: <https://www.ncbi.nlm.nih.gov/pmc/articles/ PMC2732559/> DOI: 10.3201/eid08 09.020063

GALIĖ, S., GARCÍA G. C., MIGUÉLEZ, E. M., VILLAR, C. J., LOMBÓ, F. Biofilms in the food industry: health aspects and control methods. Frontiers in microbiology, $v$. 9, p. 898, 2018. Disponível em: <https://doi.org/10.3389/fmicb.2018.00898> DOI: 10.3389/fmicb.2018.00898 
GHANBARI, A., DEHGHANY, J., SCHWEBS, T., MÜSKEN, M., HÄUSSLER, S., MEYER-HERMANN, M. Inoculation density and nutrient level determine the formation of mushroom-shaped structures in Pseudomonas aeruginosa biofilms. Scientific reports, v. 6, p. 32097, 2016. Disponível em: <https://www.nature.com/articles/srep32097.pdf> DOI: 10.1038/srep32097

HA, D-G.; O'TOOLE, G. A. c-di-GMP and its effects on biofilm formation and dispersion: a Pseudomonas aeruginosa review. Microbiology spectrum, v. 3, n. 2, 2015. Disponível em:< http://www.asmscience.org/content/journal/ microbiolspec /10.1128/microbiolspec.MB-0003-2014> DOI: 10.1128/microbiols pec.MB-0003-2014

HANEY, E., TRIMBLE, M., CHENG, J., VALLÉ, Q., HANCOCK, R. Critical Assessment of Methods to Quantify Biofilm Growth and Evaluate Antibiofilm Activity of Host Defence Peptides. Biomolecules, v. 8, n. 2, p. 29, 2018. Disponível em: <https://www.mdpi.com/2218-273X/8/2/29> DOI: 10.3390/biom 8020029

KABENGE, I., KATIMBO, A., KIGGUNDU, N., BANADDA, N. Bioremediation Technology Potential for Management of Soil and Water Pollution from Anticipated Rapid Industrialization and Planned Oil and Gas Sector in Uganda: A Review. Journal of Environmental Protection, v. 8, n. 11, p. 1393, 2017. Disponível em: <https://www.scirp.org/journal/Paperlnformation.aspx?paperlD $=80048>$ DOI: 10.4236/jep.2017.811085

KALICIŃSKA, A.; TYSKI, S. Analysis of Pseudomonas aeruginosa biofilm production in relation to cultivation media and biofilm staining methods. Medycyna doswiadczalna i mikrobiologia, v. 61 , n. 3, p. 243-252, 2009. Disponível em: <https://www.ncbi.nlm.nih.gov/pubmed/20120927>

LAILA, H. J. E. A., SANTOS, R. C. V. Aspectos gerais e mecanismos moleculares envolvidos na formação de biofilmes de pseudomonas aeruginosa. Disciplinarum Scientia Saúde, v. 17, n. 1, p. 125-144, 2016. Disponível em: $<$ https://www.periodicos.unifra.br/index.php/disciplinarum S/article/view/1914>

MASÁK, J., ČEJKOVÁ, A., SCHREIBEROVÁ, O., ŘEZANKA, T. Pseudomonas biofilms: possibilities of their control. FEMS microbiology ecology, v. 89, n. 1, p. 114, 2014. Disponível em: <https://doi.org/10.1111/1574-6941.12344> DOI: 10.1111/1574-69 41.12344

MULCAHY, L. R.; VINCENT, I.M.; LEWIS, K. Pseudomonas aeruginosa biofilms in disease. Microbial ecology, v. 68, n. 1, p. 1-12, 2014. Disponível em: <https://link.springer.com/article/10.1007/s00248-013-0297-x> DOI: 10.1007/s 00248 $-013-0297-x$

MYSZKA, K., CZACZYK, K., Characterization of adhesive exopolysaccharide (EPS) produced by Pseudomonas aeruginosa under starvation conditions. Current microbiology, v. 58, n. 6, p. 541-546, 2009. Disponível em: <https://link.springer.com/article/10.1007/s00284-009-9365-3> DOI: 10.1007/s00284009-9365-3

NAVES, P., DEL PRADO, G., HUElVES, L., GRACIA, M., RUIZ, V., BLANCO, J., SORIANO, F. Correlation between virulence factors and in vitro biofilm formation by 
Escherichia coli strains. Microbial pathogenesis, v. 45, n. 2, p. 86-91, 2008. Disponível em: <https://doi.org/10.1016/j.micpath.2008.03.003> DOI: 10.1016/j.micp ath.2008.03.003

NOWAK, J., CRUZ, C. D., PALMER, J., FLETCHER, G. C., Flint, S. Biofilm formation of the $L$. monocytogenes strain $15 \mathrm{G} 01$ is influenced by changes in environmental conditions. Journal of microbiological methods, v. 119, p. 189-195, 2015. Disponível em: <https://doi.org/10.1016/j.mimet.2015.10.022> DOI: 10.1016/j.mimet.2015.10.022

O'TOOLE, G. A. Microtiter dish biofilm formation assay. Journal of visualized experiments: JoVE, n. 47, 2011. Disponível em:< https://www.ncbi.nlm.nih.gov/ pmc/articles/PMC3182663/> DOI: 10.3791/2437

PEREZ, L. R. R.; BARTH, A. L. Biofilm production using distinct media and antimicrobial susceptibility profile of Pseudomonas aeruginosa. Brazilian Journal of Infectious Diseases, v. 15, n. 4, p. 301-304, 2011. Disponível em: <https://doi.org/10.1016/S1413-8670(11)70196-9> DOI: 10.1016/S1413-8670(11)701 96-9

QUATRIN, P. M., COMIM, V. M., LOPES, L. Q. S., GÜNDEL, A., DE ALMEIDA VAUCHER, R., SANTOS, R. C. V. Avaliação de diferentes substratos para a formação de biofilmes in vitro de Pseudomonas aeruginosa. Disciplinarum Scientia Saúde, v. 16, n. 2, p. 191-203, 2016. Disponível em: <https://www.periodicos.unifra. br/index.php/disciplinarumS/article/view/1003>

RASAMIRAVAKA, T., LABTANI, Q., DUEZ, P., EL JAZIRI, M. The formation of biofilms by Pseudomonas aeruginosa: a review of the natural and synthetic compounds interfering with control mechanisms. BioMed research international, vol. 2015, Article ID 759348, p. 17, 2015. Disponível em: <http://dx.doi.org/10.1155 /2015/759348> DOI: 10.1155/2015/759348

RIBEIRO, S. M., FELICIO, M. R., BOAS, E. V., GONCALVES, S., COSTA, F. F., SAMY, R. P., FRANCO, O. L. New frontiers for anti-biofilm drug development. Pharmacology \& therapeutics, v. 160, p. 133-144, 2016. Disponível em: <https://doi.org/10.1016/j.pharmthera.2016.02.006> DOI: 10.1016/j.pharmthera.2 016.02 .006

SHROUT, J. D., CHOPP, D. L., JUST, C. L., HENTZER, M., GIVSKOV, M., \& PARSEK, M. R. The impact of quorum sensing and swarming motility on Pseudomonas aeruginosa biofilm formation is nutritionally conditional. Molecular microbiology, v. 62, n. 5, p. 1264-1277, 2006. Disponível em: < https://doi.org/10.1111/j.1365-2958.2006.05421.x> DOI: 10.1111/j.1365-2958.2006.0 5421

SILVA, J. O.; COSTA, P. P.; RECHE, S. H. C. Manutenção de leveduras por congelamento a $20^{\circ} \mathrm{C}$. Revista Brasileira de Analises Clinicas, p. 73-74, 2008. Disponível em: < http://pesquisa.bvs.br/brasil/resource/es/lil-510681>

SPERANZA, B., CORBO, M. R. The impact of biofilms on food spoilage. In: The Microbiological Quality of Food. Woodhead Publishing, 2017. p. 259-282. 
Disponível em: <https://doi.org/10.1016/B978-0-08-100502-6.00014-5> DOI: 10.1016/B978-0-08-100502-6.00014-5

STEPANOVIĆ, S., ĆIRKOVIĆ, I., RANIN, L., VABIĆ VLAHOVIĆ, M. Biofilm Formation by Salmonella spp. and Listeria monocytogenes on plastic surface. Letters in Applied Microbiology, v. 38, n. 5, p. 428-432, 2004. Disponível em: < https://doi.org/10.1111/j.1472-765X.2004.01513.x> DOI:10.1111/j.1472-765X.2004.01 513.x

VADYVALOO, V., MARTÍNEZ, L. Mechanisms of post-transcriptional gene regulation in bacterial biofilms. Frontiers in cellular and infection microbiology, v. 4, p. 38, 2014. Disponível em: <https://doi.org/10.3389/fcimb.2014.00038> DOI: 10.3389/fcimb.2014.00038 